\title{
Produto educacional para o ensino de Probabilidade e Estatística: Stat1
}

Educational product for Teaching of Probability and Statistics: Stat1

\author{
Cristiane de Fatima Budek Dias $1^{*}$ \\ Guataçara dos Santos Junior 2* \\ Rafael Dornelles Lima 3*
}

\section{Resumo}

Este artigo apresenta o Ambiente Virtual de Aprendizagem para o ensino de Probabilidade e Estatística Stat1, desenvolvido com o intuito de auxiliar professores dos iniciais do Ensino Fundamental no processo de ensino e aprendizagem e em sua formação continuada. Tal ambiente foi desenvolvido com a participação de professores atuantes em escolas da rede municipal de ensino de Ponta Grossa/PR/Brasil, em uma pesquisa de Mestrado em Ensino de Ciência e Tecnologia. As ferramentas apresentam espaços para a interação entre professores e alunos; alunos e alunos; professores e professores; entre escolas diferentes; e entre escola e sociedade.

Palavras-chave: Professores. ensino fundamental. probabilidade. estatística.

This article presents the Virtual Learning Environment for teaching of Probability and Statistic Stat1, developed with the purpose of assisting teachers of the Elementary School in the process of teaching and learning, and in their continuing training. This environment was developed with the participation of teachers working in municipal schools of Ponta Grossa / PR / Brazil, in a Master's Degree in Science and Technology Teaching. The tools enable the interaction between teachers and students; students and students; teachers and teachers; between different schools; and between school and society.

Keywords: Teachers. elementary school. probability. statistic.

\section{Introdução}

O conhecimento estatístico assume cada vez mais relevância para a formação integral do cidadão, uma vez que, a alfabetização, na sociedade atual, requer o domínio da leitura e da interpretação de dados, assim como o

* Doutoranda em Ensino de Ciência e Tecnologia pela Universidade Tecnológica Federal do Paraná (UTFPR - Ponta Grossa), cristianed@alunos.utfpr.edu.br

* Doutor em Ciências Geodésicas, Professor do Programa de Pós-Graduação em Ensino de Ciência e Tecnologia da Universidade Tecnológica Federal do Paraná (UTFPR - Ponta Grossa), guata@ utfpr.edu.br

* Especialista em Desenvolvimento Web, Professor da Faculdade Educacional da Lapa (FAEL), rafaeldornelleslima@gmail.com 
conhecimento dos processos de recolhimento, análise e tomada de decisões (BRASIL, 1997, p. 84).

Nesse sentido, é crucial que, já no início da escolarização, os estudantes tenham contato com conceitos estatísticos e probabilísticos e isso precisa ser realizado de diferentes formas e com uso de diversas ferramentas, priorizando-se um ensino que atenda ao contexto atual.

Recorrente aos estudos realizados pelos autores deste trabalho, levantouse como aporte para os professores, a introdução das tecnologias na sala de aula, a fim de contribuir com o processo de ensino e aprendizagem da estatística e probabilidade nos anos iniciais do ensino fundamental.

As tecnologias, podem trazer facilidades para a compreensão da lógica das representações dos dados e, também, podem representar ganho significativo de tempo, que poderá ser melhor aproveitado com reflexões sobre as informações coletadas e acerca de possíveis ações diante das conclusões conseguidas com os dados levantados (BATANERO, DIAZ, 2013; LIRA, MONTEIRO, 2011; BENZVI, 2011).

Entretanto, introduzir computadores na escola não é garantia de eficiência no ensino de Estatística, pois as abordagens pedagógicas e os softwares utilizados precisam ser observados (LIRA, MONTEIRO, 2011). Dessa forma, conhecer as ferramentas e fazer a escolha correta das mesmas é imprescindível, assim como as práticas didáticas a partir dessa escolha. Em outras palavras, o professor precisa saber qual ferramenta utilizar e como abordar os conceitos estatísticos e probabilísticos tendo como base o software escolhido, apropriandose de suas características, selecionando aqueles mais pertinentes aos objetivos de ensino e às particularidades de seu grupo de alunos (CAMPÊLO, 2014). É nesse sentido que se entende a necessidade de colocar os professores em uma participação mais ativa tanto na elaboração do software, como, em sua avaliação, enquanto instrumento didático-pedagógico.

À vista disso, a pesquisa que originou o produto educacional aqui apresentado, partiu da problemática de como se construir um Ambiente Virtual de 
Aprendizagem para o ensino de Probabilidade e Estatística nos anos iniciais do Ensino Fundamental, considerando os documentos curriculares oficiais e as práticas docentes. Assim, todo processo de construção esteve atrelado ao campo de atuação docente e às suas necessidades, considerando-se currículo e prática.

Deste modo, este artigo apresenta o Ambiente Virtual de Aprendizagem para o ensino de Probabilidade e Estatística Stat1, desenvolvido com o intuito de auxiliar professores dos anos iniciais do Ensino Fundamental no processo de ensino e aprendizagem e em sua formação continuada. Tal ambiente foi desenvolvido em uma pesquisa de Mestrado em Ensino de Ciência e Tecnologia e contou com a participação de professores atuantes em escolas da rede municipal de ensino de Ponta Grossa/PR/Brasil.

O texto do artigo é um recorte da pesquisa realizada, focando os aspectos procedimentais da construção do AVA, denominado Stat1, e a participação dos professores nesse processo.

\section{Detalhamento: caminhos de construção do Ambiente Virtual de Aprendizagem Stat1}

A proposta de construir um AVA surgiu durante as discussões no grupo de pesquisa de Ensino de Probabilidade e Estatística da Universidade Tecnológica Federal do Paraná (UTFPR/Ponta Grossa). A intenção era a construção de uma ferramenta tecnológica que fosse útil para alunos e professores dos anos iniciais do Ensino Fundamental e que agregasse conteúdos estatísticos e metodologias que oportunizassem a aprendizagem por meio da investigação.

Em um primeiro momento a ideia era construir a ferramenta e depois formar os professores para seu uso, porém, durante a aplicação de alguns instrumentos diagnósticos (questionários e sondagens) e com as leituras dos referenciais teóricos pertinentes à linha de pesquisa (principalmente Almeida (2012) e Mishra; Koehler $(2006,2008)$ ) , percebeu-se a necessidade de que os professores participassem de maneira mais ativa nessa construção para que houvesse uma contribuição mais efetiva da pesquisa no desenvolvimento do 
Conhecimento Pedagógico e Tecnológico do Conteúdo (MISHRA; KOEHLER, 2006) dos professores participantes.

Assim, seguiu-se um outro caminho e, para a construção do Stat1 foram realizadas pesquisas com professores atuantes nos anos iniciais do Ensino Fundamental, análise dos Parâmetros Curriculares Nacionais (PCN) brasileiros e das Diretrizes Curriculares Municipais de Ponta Grossa/Paraná/Brasil. O primeiro passo de construção se deu com a análise dos documentos curriculares citados e com a aplicação de questionários a trinta e sete (37) professores de seis escolas da rede municipal de ensino.

O intuito dos questionários foi levantar quais eram os conceitos estatísticos e probabilísticos abordados pelos professores em suas aulas e como o ensino de tais conceitos ocorria, ou seja, quais eram as ferramentas e metodologias utilizadas pelos docentes.

Após essa fase inicial, foi organizado um protótipo do ambiente, que foi apresentado em um encontro de coparticipação no desenvolvimento do AVA, que ocorreu no final do mês de novembro de 2015 em uma escola da rede municipal, contando com a participação de dezessete (17) professores.

$O$ encontro seguiu um roteiro previamente estabelecido, sendo que cada uma das ferramentas cogitadas (a priori) para o AVA foram apresentadas aos professores, seguindo-se para a discussão sobre funcionalidades e instigando-se a indicação de propostas de melhorias e adequações. Os professores, então, deveriam pensar sobre o conteúdo para colaborar com o levantamento de requisitos (funcionalidades) do AVA, indicando usos pedagógicos que fariam da ferramenta para que a mesma pudesse atender aos seus anseios e facilitar a aprendizagem.

A coleta dos dados para a finalização do Stat1 foi realizada por meio de cartões em que os professores deveriam escrever o que desejavam para cada uma das ferramentas (melhorias, aprofundamentos, novas ferramentas, etc) e o porquê de tal solicitação. Assim, cada cartão trazia espaço para a indicação da ferramenta, seguida da frase "Eu como professor quero. , porque. 
Neste artigo são apresentadas cada uma das ferramentas, suas relações com os documentos curriculares oficiais, com o referencial teórico estudado no início da pesquisa, e com alguns dos anseios dos professores participantes da pesquisa, descritos nos cartões durante o encontro. Esses cartões foram codificados com a letra $\mathrm{C}$ seguida de um número $1 ; 2 ; 3 \ldots 17$.

\section{O Stat1 e relações de construção e uso}

Há seis ferramentas no AVA Stat1: Conceitos; Pesquisa; Blog; Plano de Aula; Leitura e Fórum. Algumas destas podem ser acessadas pelo público em geral (Conceitos; Blog; Plano de Aula) e outras são restritas, permitindo acesso e gerenciamento apenas a usuários cadastrados como professores e/ou alunos (Pesquisa; Leitura e Fórum). A Figura 1 apresenta a página inicial do Stat1.

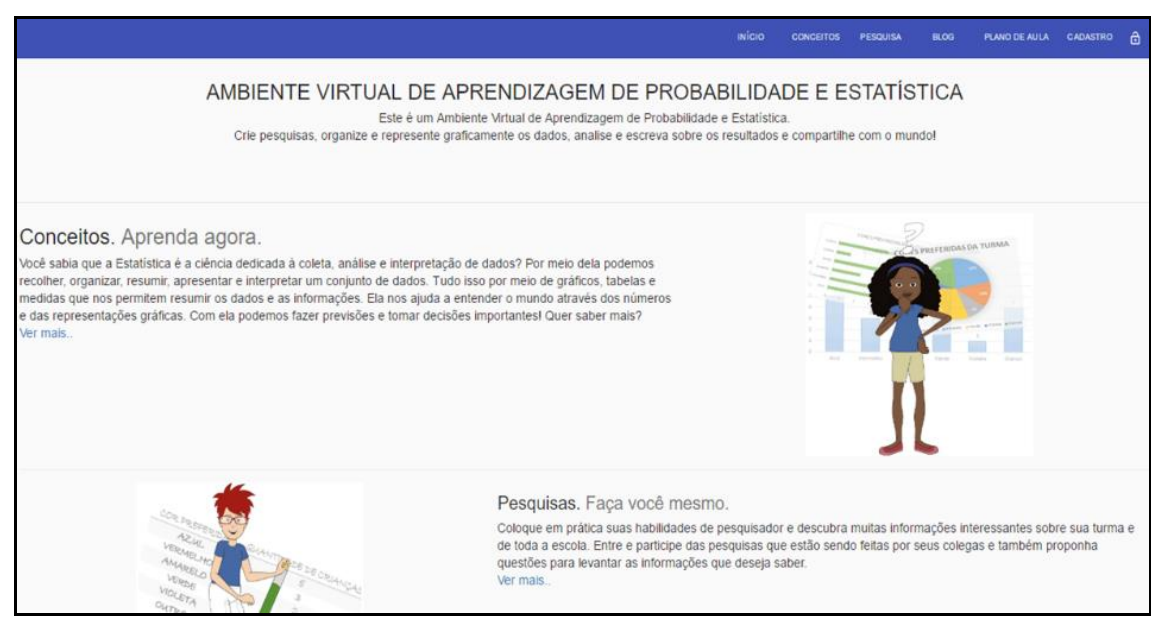

Figura 1. Tela inicial do Stat1.

Fonte: Stat1, 2016.

Existem áreas específicas para cada perfil de usuário. Aos professores é delegada a tarefa de cadastro de turmas e alunos para que as atividades interativas possam ser realizadas por estes últimos dentro do AVA.

A ferramenta Conceitos (Figura 2) é um espaço destinado à apresentação de alguns conceitos referentes à Probabilidade e Estatística. Entende-se de que nos anos iniciais a criança desenvolve a capacidade para aprendizagem de conceitos matemáticos básicos (BRASIL, 2013, p. 110), assim, alguns conceitos 
probabilísticos e estatísticos necessitam ser introduzidos, para que consiga realizar uma leitura da realidade, agindo coerentemente sobre a mesma.

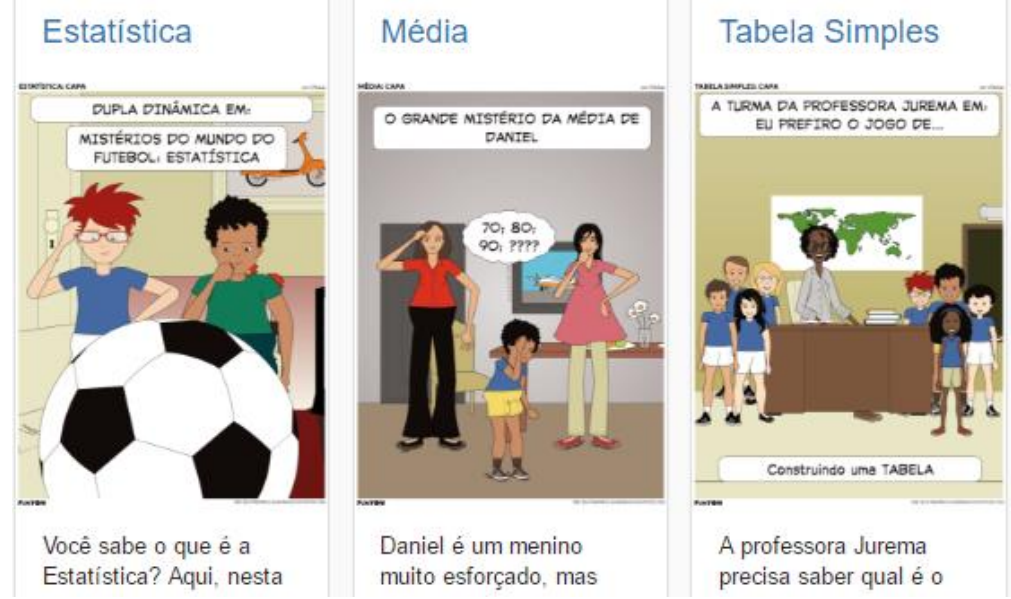

Figura 2: Tela da ferramenta Conceitos

Fonte: Stat1, 2016.

A organização dos conceitos foi proposta por meio de histórias em quadrinhos, elaboradas no software Pixton. Acredita-se que essa pode ser uma maneira de introduzir conceitos e conteúdos com a apresentação de seu uso em situações corriqueiras da vida diária, demonstrando que a Probabilidade e Estatística estão presentes nas mais diversas situações.

Foram considerados, nesta ferramenta, os conteúdos propostos pelos PCN (BRASIL, 1997) e pelas Diretrizes Curriculares Municipais (PONTA GROSSA, 2015) para os anos iniciais. Merece destaque, o conceito de Média Aritmética, proposto pelos PCN (BRASIL, 1997) e que é um conceito importante para que os alunos consigam relacioná-lo à realidade (MARQUES, GUIMARÃES, GIRITANA, 2011). As Diretrizes Curriculares Municipais (PONTA GROSSA, 2015), não trazem a Média Aritmética como um conceito a ser abordado no bloco de conteúdos Tratamento da Informação, dessa forma, a inserção do mesmo na ferramenta Conceitos pode ser importante para que se tenha um aporte e um aprofundamento das práticas dos professores ao trabalharem com a Probabilidade e Estatística em suas aulas. 
Há a possibilidade de impressão das histórias, aspecto solicitado pelos professores participantes da pesquisa, o que permite que, mesmo que os professores não possuam acesso a um laboratório de informática na escola, poderão utilizar das histórias do Stat1 para o ensino de Probabilidade e Estatística, seja como motivação para a aula, ou como introdução ao conteúdo.

A ferramenta Pesquisa (Figura 3) é um espaço que possibilita a interação com as etapas de uma investigação Estatística (entendida de acordo com: Lopes 2003; Silva, 2013; Guimarães, 2014), permitindo que professores e alunos construam um instrumento de pesquisa e que coletem dados a partir do mesmo. Ainda, é possível responder a pesquisas e visualizar as já realizadas.

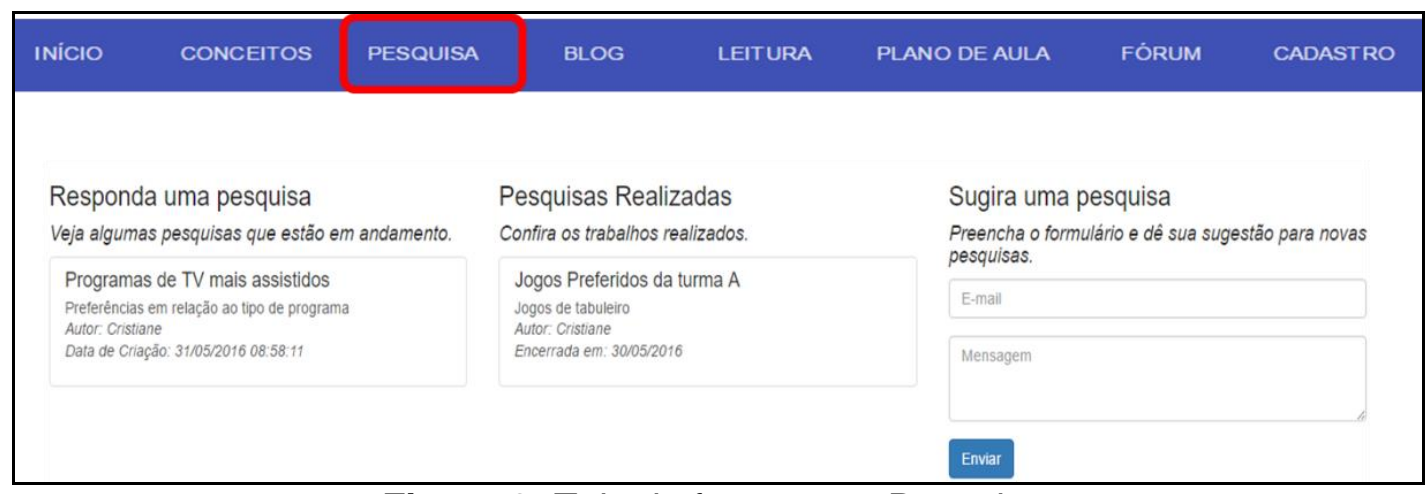

Figura 3: Tela da ferramenta Pesquisa.

Fonte: Stat1, 2016.

Esta ferramenta pode atender ao trabalho dos conteúdos de coleta, organização e descrição de dados; leitura, interpretação e análise de dados representados em tabelas e gráficos; a construção de tabelas simples e de dupla entrada; construção de gráficos de barras, colunas e setores; a leitura desses tipos de representações gráficas e, também, das representações em gráficos lineares (BRASIL, 1997; PONTA GROSSA, 2015).

Com as atividades realizadas nesta ferramenta, ainda, pode ser possível explorar a obtenção e a interpretação da média aritmética (BRASIL, 1997b); a interpretação de dados em representações gráficas e tabulares para a identificação das características previsíveis ou aleatórias dos acontecimentos (BRASIL, 1997; PONTA GROSSA, 2015). 
A ferramenta é composta de um espaço de "Pesquisas Realizadas", ou seja, pesquisas já realizadas por outros usuários cadastrados; banco de dados com gráficos, tabelas e descrições do resultado. Um espaço denominado "Pesquisas em Andamento", no qual estão armazenadas pesquisas que podem ser respondidas por usuários cadastrados e não cadastrados. Um espaço "Criar Pesquisa" que permite a criação de pesquisas, com a elaboração de perguntas e alternativas para as respostas; a publicação para a obtenção de respostas; a tabulação e a representação gráfica.

O acesso a essa ferramenta é permitido a usuários cadastrados (professores e alunos) para o gerenciamento e a criação de pesquisas. Aos usuários não cadastrados é permitida a visualização das pesquisas já realizadas e, também, é facultado o acesso às que estão em andamento.

Com a apresentação da proposta inicial da ferramenta Pesquisa, surgiram algumas possibilidades e adequações, sendo que, os professores apontaram o desejo por diferentes formas de representação dos dados: quero "que a pesquisa apareça de diversas maneiras"; porque "o aluno poderá visualizar os dados com gráficos variados, permitindo ele tenha uma visão ampla dos dados"(C6). A pesquisa de Campêlo (2014) denota que, as diferentes formas de visualização e de representação dos dados, permite que os educandos percebam qual a melhor forma de representá-los para que a leitura e a interpretação sejam facilitadas. Dessa forma, essa sugestão foi considerada e, no momento em que o aluno tabula a pesquisa e vai para a geração do gráfico, diferentes tipos de representações gráficas são indicados para a escolha na ferramenta (barras/setores/lineares), possibilitando a exploração e a opção por aquela que melhor representa os dados.

Acredita-se que essa pode ser uma das particularidades facilitadas quando se faz uso das TIC no processo de construção de gráficos, Lira e Monteiro (2008) afirmam que isso possibilita o desenvolvimento das habilidades de interpretação antes do formalismo do desenho dos gráficos. Ademais, pode trazer mudanças na lógica curricular, ultrapassando-se a hierarquia (LIRA, MONTEIRO, 2008) e a 
linearidade dos conteúdos (BIANCHINI, 2014). É por isso, que na ferramenta, além dos gráficos de barras e colunas, também, há a possibilidade da representação dos dados em gráficos de setores e de linhas, indicados nos documentos apenas para leitura e interpretação e somente no segundo ciclo.

A ferramenta Blog (Figura 4) é um espaço de compartilhamento de informações a respeito dos trabalhos realizados na turma (investigações estatísticas). $O$ intuito é que sejam realizadas análises sobre os dados coletados e que a turma possa descrever essas análises e as conclusões, utilizando-se das terminologias probabilísticas e estatísticas adequadas. É, ainda, um espaço para pesquisa e conhecimento.

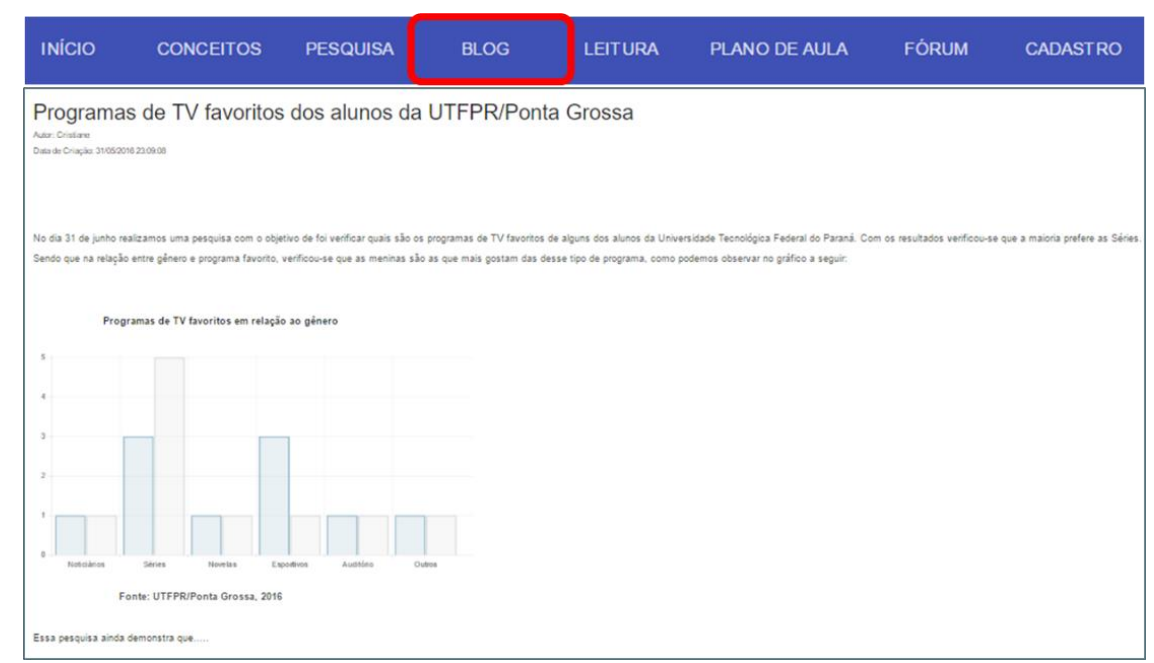

Figura 4: Tela da ferramenta Blog.

Fonte: Stat1, 2016.

Tanto nos PCN (BRASIL, 1997) como nas Diretrizes Curriculares Municipais (PONTA GROSSA, 2015) há menção à produção escrita partindo de gráficos e tabelas. Entende-se que é crucial que os alunos sejam capazes de comunicar efetivamente os resultados de suas pesquisas e que realizem discussões sobre os mesmos, analisando, criticando e apontando caminhos com base em dados, fazendo uso de terminologias estatísticas e probabilísticas corretamente (LOPES, 2008). Então, nesta ferramenta possibilita-se que textos sejam criados e, também, publicados. 
É nesse espaço que docentes e discentes poderão ter a oportunidade de gerar informações para conhecimento de seus colegas de outras turmas, assim como, para um público mais amplo. Essa é uma maneira do aluno ser ativo na geração de conhecimentos, publicando informações que poderão ser úteis para outras pessoas. Essa perspectiva é uma tentativa de superação da visão de alunos e professores como mero consumidores de informações (PONTE, 2000; KENSKI, 2012). Ademais, pode ser uma forma de possibilitar a interação e a integração com novas comunidades (PONTE, 2000).

Tanto usuários cadastrados, quanto não cadastrados terão acesso aos textos postados no Blog, porém, somente usuários cadastrados (professores e alunos) poderão escrever tais textos. A publicação fica restrita aos professores, ou seja, professores e alunos poderão criar posts (textos) para o Blog, mas, somente o professor poderá publicá-los. Os posts criados pelos alunos serão encaminhados para o professor para que o mesmo possa fazer a correção.

Esta foi uma das ferramentas que gerou mais discussão entre os professores, aparentemente, com uma boa aceitação. Além disso, o fato da ferramenta ser semelhante àquelas dos Blogs convencionais, conhecidos por muitos dos participantes da pesquisa, pode ter facilitado a compreensão do que se propunha. Também, na turma de professores havia alguns com intensa participação nessas ferramentas, como meio de divulgação de seus trabalhos.

Um dos cartões traz uma colocação que sugere a percepção das possibilidades que o Blog pode trazer para o processo de ensino e aprendizagem de Probabilidade e Estatística: quero "que continue o Blog e a exposição das pesquisas no mesmo" porque "para comparar as diversas informações e estudos que estão sendo realizados" (C5). Subentende-se que o Blog pode trazer oportunidades únicas para que muitas correlações entre os resultados das pesquisas possam ser realizadas. Esse aspecto pode oportunizar muitas discussões em sala de aula, proporcionado as inferências e as tomadas de decisão a partir de resultados estatísticos e probabilísticos. 
O Blog, também, pode ser muito útil no trabalho com a transnumeração, aspecto levantado pelos professores respondentes do questionário como uma das maiores dificuldades dos alunos no trabalho com a construção de gráficos e tabelas. Entende-se que, com base nos textos publicados, os professores podem organizar atividades que trabalhem essa habilidade. Além disso, acredita-se que ao coletar, organizar e representar os dados na ferramenta de Pesquisa, isso já estará colocando os alunos a par da lógica das representações, o que poderá facilitar a construção de gráficos e tabelas a partir de dados contidos em outros textos (conteúdo proposto nos PCN (BRASIL, 1997) e nas Diretrizes Curriculares Municipais (PONTA GROSSA, 2015)).

Ao expor os trabalhos de Probabilidade e Estatística realizados com os alunos, nesta ferramenta, considera-se que pode haver a abertura de um espaço de comunicação com a sociedade na perspectiva apontada por Nóvoa (2009), reforçando a profissão docente e sua relevância para a formação crítica do cidadão.

A Ferramenta Plano de Aula (Figura 5) é um espaço para a divulgação de planos de aula que se utilizem do AVA para o ensino de Probabilidade e Estatística. É uma proposta para que os professores compartilhem suas ideias e possam fazer uso das propostas de outros docentes.

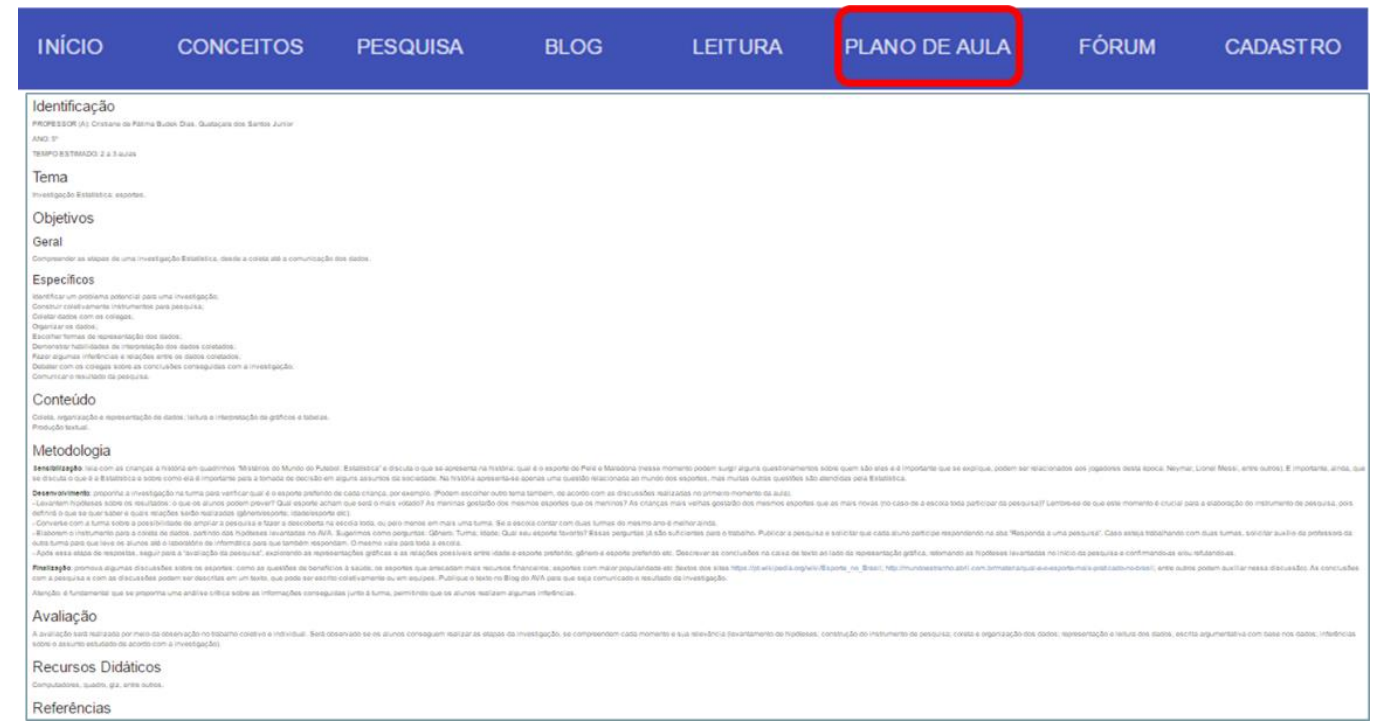

Figura 5: Tela da ferramenta Plano de Aula. 
Fonte: Stat1, 2016

Essa ferramenta foi pensada para que os professores, além da comum pesquisa realizada pelos mesmos na procura por "ideias" de trabalho, da mesma forma, sejam produtores dessas ideias. A Internet pode abrir essa possibilidade de interação e troca de conhecimento que é fundamental ao professor da atualidade (PONTE, 2000)

A ferramenta de criação dos planos possui um modelo pré-definido que traz alguns passos considerados importantes a um planejamento: especificação da turma a que se destina; tempo de duração da aula; conteúdos a serem abordados; objetivos gerais e específicos das atividades propostas; metodologia a ser empregada para se atingir aos objetivos; forma de avaliação da aprendizagem que indique se os objetivos foram ou não atingidos e os materiais a serem utilizados em cada uma das tarefas planejadas. Também, é possível identificar a autoria dos planos e indicar as referências bibliográficas consultadas.

Os planos são de acesso a todos (usuários cadastrados e não cadastrados), pois, foi o desejo da maioria dos participantes da pesquisa. $O$ anseio de que os planos sejam abertos a todos é justificado em um dos cartões da seguinte maneira: porque "partilhar um trabalho que deu certo e poder utilizar ideias novas" (C1). Acredita-se que esse "compartilhamento de ideias" pode ser um dos pontos centrais desta ferramenta, posto que, professores novos ao cadastrarem-se no Stat1, poderão visualizar possibilidades de trabalho dentro do ambiente, tendo exemplos de como trabalhar com seus alunos a partir da utilização do AVA.

A ferramenta Leitura (Figura 6) constitui-se em um espaço com textos e links de referências externas que tratam dos conteúdos de Probabilidade e Estatística: artigos, pesquisas, vídeos, entre outros. Essa ferramenta foi pensada com o intuito de auxiliar o professor na busca por sua própria formação, considerando que a leitura pode trazer conhecimentos indispensáveis para o ensino da temática. 


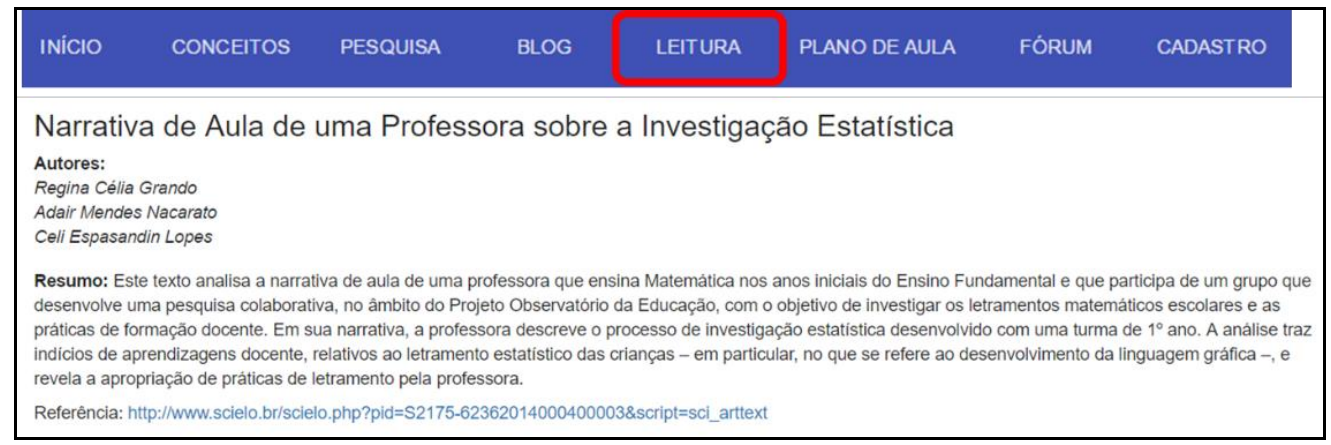

Figura 6: Tela da ferramenta Leitura, Fonte, Stat1, 2016.

O acesso e gerenciamento da ferramenta se dará apenas para usuários cadastrados como professores, ou seja, somente professores poderão indicar textos neste espaço. A proposta inicial é que sejam indicados os links, com o título e uma breve descrição do texto e/ou do vídeo.

A Leitura foi proposta para que os professores possam aprofundar-se no tema e para que possam vir a refletir sobre o processo de ensino e sobre a aprendizagem de Probabilidade e Estatística, ponderando sua importância na sociedade atual (BRASIL, 1997; PONTA GROSSA, 2015) e na formação cidadã de seus alunos (PONTE, FONSECA, 2001; LOPES, 2008; AMARANTE 2011).

Essa ferramenta pode possibilitar aos professores, a partir da leitura de outros materiais, a reflexão sobre seu próprio trabalho. E, do mesmo modo, pode propor aos professores uma participação ativa em sua própria formação (NÓVOA, 2012). Outrossim pode ser uma maneira de contribuir com a formação dos colegas, com a colegialidade e com a partilha. (NÓVOA, 2009).

De acordo com a ideia central desta ferramenta, os professores serão os continuadores da mesma, ou seja, serão os protagonistas na indicação de textos e demais materiais oportunos a seus colegas. Assim sendo, caberá aos mesmos a seleção de textos e conteúdos úteis a todos.

A ferramenta Fórum (Figura 7) é semelhante aos fóruns comumente encontrados em ambientes virtuais. Composta de um espaço que possibilita a postagem de dúvidas e a troca de experiências entre os docentes. $\mathrm{O}$ acesso e $\mathrm{o}$ gerenciamento desta ferramenta são possibilitados aos usuários cadastrados 
como professores, que terão a oportunidade de incluir temas de discussão e comentar as postagens dos colegas.

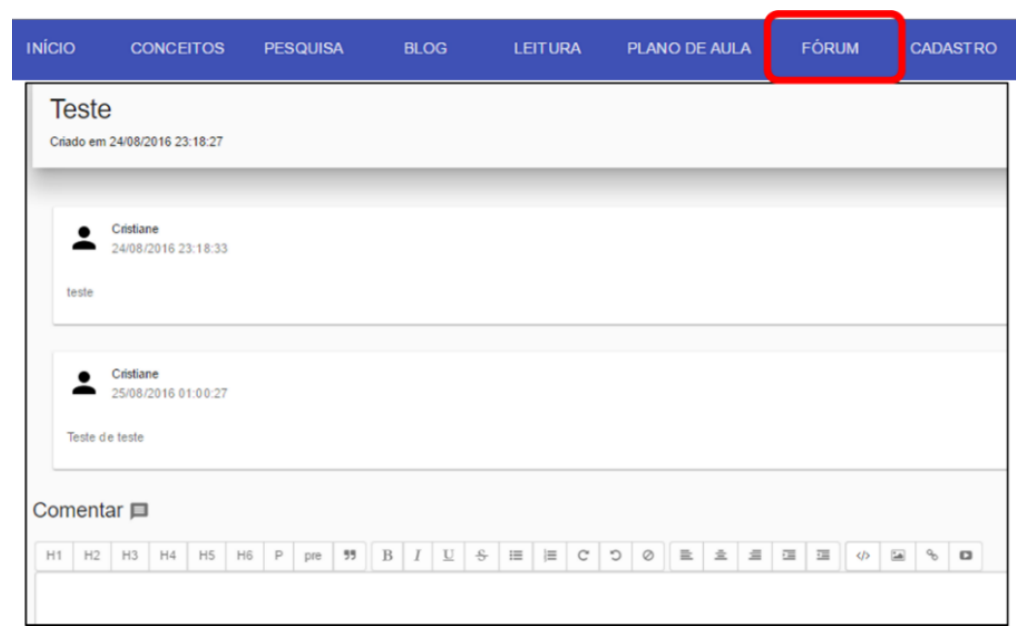

Figura 7: Tela da ferramenta Fórum.

Fonte: Stat1, 2016

Uma das questões levantadas durante as discussões versa sobre a viabilidade de agregar nesse espaço "temas para debates" (C17); "propostas para reflexão e formação continuada" (C3). Essas ideias são pertinentes e podem indicar a percepção sobre as perspectivas possibilitadas com a ferramenta.

Nela poderão ser esclarecidas dúvidas acerca de conteúdos e práticas no campo da Educação Estatística: "acho interessante para esclarecer as dúvidas com temas relacionados sobre o assunto" (C5). Além disso, os debates e questões sugeridas "facilita a reflexão dos professores sobre o processo de aprendizagem" (C17).

Refletir sobre a aprendizagem dos alunos em Probabilidade e Estatística pode ser um passo fundamental para que as práticas estejam cada vez mais voltadas para esse fim e, não apenas, ao cumprimento do currículo estabelecido. Considera-se, portanto, que esta pode ser, também, uma ferramenta oportuna para a formação continuada dos professores.

\section{Potencial de uso do Stat1}


Buscou-se pela criação de ferramentas que permitissem espaços de interação entre professores e alunos; alunos e alunos; professores e professores; entre escolas diferentes; e entre escola e sociedade. Assim, as ferramentas trazem conceitos, espaços para a edição de informações, para a realização de pesquisas, para a formação continuada e para a interatividade entre colegas de profissão.

As ferramentas Plano de Aula, Leitura e Fórum configuram-se como contributos que, juntos, podem atender, mesmo que parcialmente, às necessidades preliminares de formação continuada dos professores em relação à temática, observadas nos questionários e no encontro de coparticipação no desenvolvimento do AVA.

Entende-se que, essas ferramentas, baseiam-se na autonomia, na colegialidade e no atendimento à dimensão pessoal do professor, conforme propõe Nóvoa (2009). Da mesma forma, caracterizam uma formação contínua, flexível, autônoma e coletiva (CERNY, ALMEIDA; RAMOS, 2014). Uma formação contínua por pressupor o não encerramento das atividades, posto que, cada uma das ferramentas caminha para um processo ininterrupto de publicação e participação docente. A flexibilidade, pelo fato da disponibilização de conteúdos de acordo com as necessidades de cada escola e/ou professor. A autonomia, que aponta a escola como instituição formadora e o professor como agente de formação de si próprio e dos colegas. Tudo isso, possibilitando a ação coletiva. Ou, como coloca Nóvoa (2009): a construção das "culturas colaborativas".

As ferramentas Conceitos; Pesquisa e Blog trazem instrumentos que podem facilitar a abordagem da Probabilidade e Estatística em uma dimensão que vai além do determinismo, da linearidade, do tecnicismo e das fórmulas. No desenvolvimento das mesmas, buscou-se por meios em que fosse possibilitado ao aluno o desenvolvimento do espírito investigativo e da capacidade de utilizar conhecimentos probabilísticos e estatísticos para a interpretação e ação na realidade. 
É evidente, que essa pretensão dependerá da realização de atividades significativas dentro das ferramentas e dos conteúdos de Probabilidade e Estatística. Caberá aos professores, a partir de discussões com os colegas (Fórum) e da leitura dos textos postados (Formação e Plano de Aula), reflexões e planejamentos que motivem os alunos na proposição de questionamentos, na elaboração de hipóteses e na tentativa de responder a problemas cotidianos por meio do conhecimento probabilístico e estatístico.

O Stat1, por sua natureza interativa e de complementação, não é um instrumento pronto e acabado, posto que, estará sempre em processo de construção, que se dará por meio da interação de professores e alunos e de professores e professores na ferramenta. As propostas de formação continuada poderão ser constantes, professores e professores e, também, pesquisadores poderão inserir conteúdos e trocar experiências para que se enriqueça o trabalho com a Probabilidade e Estatística nas escolas.

\section{Considerações Finais}

O processo de construção do AVA Stat1 revelou que há muitas dificuldades de aceitação quando se busca por outras formas para o desenvolvimento de ferramentas tecnológicas para o ensino e, também, de novas propostas formativas. Acredita-se que isso se deva ao fato da finalidade com que se apresentou o encontro de coparticipação no desenvolvimento, pois, geralmente 0 que ocorre é os professores serem apresentados a ferramentas prontas, em que são "treinados" para seu uso no decorrer do trabalho docente. O que se propôs foi uma inversão desse modelo, apresentando uma ferramenta em fase de construção, em que suas opiniões e anseios seriam considerados. O intuito sempre foi o de ouvir os professores e de colocá-los como (co)construtores da ferramenta.

Apesar disso, ficou evidente que a participação dos professores no processo de desenvolvimento de recursos tecnológicos pode ser fundamental para que esses recursos sejam, realmente, desenvolvidos com atenção aos 
anseios dos professores e à realidade da sala de aula. As discussões sobre as ferramentas geraram reflexões, percepções e sugestões com contributos significativos para a melhoria da ferramenta e para que ela viesse a atender de forma mais efetiva algumas das necessidades dos professores.

O intuito de colocar os professores como construtores e não meros usuários pode ser um caminho viável para que os softwares educacionais venham atender de forma mais efetiva a realidade das escolas e, ainda, contribui de maneira significativa para uma formação continuada mais abrangente.

Com a pesquisa realizada para o desenvolvimento do Stat1, foi possível concluir que o processo de construção contempla alguns elementos cruciais: conhecer o currículo; conhecer o conteúdo; conhecer as abordagens pedagógicas e conhecer prática docente.

O conhecimento do currículo é importante para que se contemplem conteúdos que estejam de acordo com aquilo que é de direito a todos. $\mathrm{O}$ conhecimento do conteúdo permitiu que as ferramentas fossem delineadas de acordo com as peculiaridades do conhecimento probabilístico e estatístico. $\mathrm{O}$ conhecimento das abordagens pedagógicas para o ensino de Probabilidade e Estatística foi fundamental para que ferramentas do AVA fossem projetadas de forma a favorecer o processo de ensino e aprendizagem, agregando às mesmas, aspectos como a interação, a participação ativa nos momentos de coleta, organização, representação, leitura e interpretação de dados. O conhecimento da prática docente é essencial para que se consiga fazer uma relação daquilo que deve ser trabalhado com aquilo que realmente é abordado em sala de aula. Com esse conhecimento, foi possível a inserção de ferramentas no AVA que abordam os conceitos pouco trabalhados; aqueles em que os professores e alunos sentem mais dificuldades e, além disso, propor novas formas de trabalho com os mesmos.

Não se pode desconsiderar, porém, a necessidade de um olhar crítico sobre os elementos citados, pois, é preciso considerar as lacunas nos documentos curriculares e as resistências às TIC, muitas vezes, encontradas nos 
discursos docentes. Da mesma forma, é elementar o apoio de uma equipe multidisciplinar, com professores da área da Matemática, pedagogos, professores em exercício e com profissionais da área da Informática.

Vale destacar que o Stat1 está em processo de implantação no servidor da universidade em que foi desenvolvido e, em breve, estará disponível. A pesquisa com o ambiente está em continuidade e neste ano está sendo delineado o primeiro curso de formação continuada a ser realizado no mesmo município em que foi desenvolvido. Além disso, outras ferramentas serão implementadas para que se possibilitem novas maneiras de interação e avaliação da aprendizagem no Stat1.

\section{Referências}

ALMEIDA, F. J. de. Educação e Informática: os computadores na escola. 5ed. São Paulo: Cortez, 2012.

AMARANTE, A. A. O uso do TinkerPlots para a exploração de dados por professores de escolas rurais. $156 \mathrm{f}$. Mestrado em Educação Matemática e Tecnológica - Centro de Educação, Universidade Federal de Pernambuco, Recife, 2011.

BATANERO, C.; DÍAZ, C. (Org.) Estadística con proyectos. Departamento de Didáctica de la Matemática Facultad de Ciencias de la Educación Universidad de Granada, 2013.

BEN-ZVI, D. Statistical reasoning learning environment. EM TEIA - Revista de

Educação Matemática e Tecnológica Iberoamericana, Recife, v. 2, n. 2, pp. 1-13. 2011. Disponível em: <http://www.gente.eti.br/edumatec/>. Acesso em: 29 jul. 2016.

BIANCHINI, D. F. Perspectiva da estatística como elemento norteador do trabalho com conceitos matemáticos nos anos iniciais - questões epistemológicas e de formação. In: X ANPED SUL, 10, pp. 1-16, Florianópolis (SC). Anais... Universidade do Estado de Santa Catarina - UDESC. 2014. Disponível em: http://xanpedsul.faed.udesc.br/arq pdf/193$\underline{0 . p d f}$. Acesso em: 29 jul. 2015.

BRASIL. Ministério da Educação, Secretaria da Educação Básica. Diretrizes

Curriculares Nacionais Gerais da Educação Básica. Brasília. 2013, 546p.

BRASIL. Ministério da Educação. Secretaria do Ensino Fundamental. Parâmetros Curriculares Nacionais: Matemática, $1^{\circ}$ e $2^{\circ}$ ciclos do ensino fundamental. Brasília. 1997, 88p.

CAMPÊLO, S. R. de C. Software educativo Tinkerplots 2.0: possibilidades e limites para a interpretação de gráficos por estudantes do Ensino Fundamental. $167 \mathrm{f}$. 
Mestrado em Educação Matemática e Tecnológica - Centro de Educação, Universidade Federal de Pernambuco. Recife, 2014.

CERNY, R. Z.; RAMOS, E.; ALMEIDA, J. N. de. Formação continuada de professores para a cultura digital. Revista Científica e-curriculum, São Paulo, v. 12, n. 2, pp. 13311347. 2014. Disponível em:

<http://revistas.pucsp.br/index.php/curriculum/article/view/20425>.Acesso em 20jun. 2015.

GUIMARÃES, G. Estatística nos anos iniciais. Salto para o Futuro. Ano XXIV - Boletim 6 - SETEMBRO 2014. Disponível em: <

http://tvescola.mec.gov.br/tve/salto/edition;jsessionid=17B4BBD44DF526EC9F0FBCB929 5C826F?idEdition=8168>. Acesso em: 29 jun. 2015.

KENSKI, V. M. Educação e Tecnologias: o novo ritmo da informação. 8모 ed. Campinas, SP: Papirus, 2012.

LIRA, O. C. T.; MONTEIRO, C. E. F. Interpretação de Dados a partir da Utilização de Ferramentas do Software TinkerPlots. Bolema: Boletim de Educação Matemática, Rio Claro/SP, v. 24, n. 40, pp. 765-788, 2011. Disponível em:

$<$ http://www.periodicos.rc.biblioteca.unesp.br/index.php/bolema/article/view/5293>. Acesso em: 9 maio 2015.

LIRA, O. C. T.; MONTEIRO, C. E. F. Uso do computador na construção e interpretação de gráficos nos anos iniciais do ensino fundamental. In: 2o SIPEMAT - SIMPÓSIO INTERNACIONAL DE PESQUISA EM EDUCAÇÃO MATEMÁTICA, pp. 1-7. Recife (PE). Anais... Universidade Federal Rural de Pernambuco. 2008. Disponível em: $<$ http://www.gente.eti.br/lematec/CDS/SIPEMAT08/?info_type=poster\&lang_user=en\&the me=theme3 $>$. Acesso em: 9 maio 2015.

LOPES, C. A. E. O conhecimento profissional dos professores e suas relações com estatística e probabilidade na educação infantil. $281 \mathrm{f}$. Doutorado em Educação Faculdade de Educação, Universidade Estadual de Campinas, Campinas, 2003. Disponível em: <http://www.pucrs.br/famat/viali/tic_literatura/teses/Lopes_CAE.pdf>. Acesso em: 24 abr. 2015.

LOPES, C. E. O ensino da estatística e da probabilidade na educação básica e a formação dos professores. Cadernos CEDES, Campinas, v. 28, n. 74, pp. 57-73, 2008. Disponível em:

$<$ http://www.scielo.br/scielo.php?script=sci_abstract\&pid=S010132622008000100005\&lng =en\&nrm=iso\&tlng=pt>. Acesso em: 4 jun. 2015.

MARQUES, M.; GUIMARÃES, G.; GITIRANA, V. Compreensões de alunos e professores sobre média aritmética. Bolema, Rio Claro/SP, v. 24, n. 40, pp. 725-745. 2011.

Disponível em:

<http://www.periodicos.rc.biblioteca.unesp.br/index.php/bolema/article/view/5291 >. Acesso em: 10 mai 2015. 
MISHRA, P.; KOEHLER, M. M. J. Technological Pedagogical Content Knowledge: A Framework for Teacher Knowledge. In: Teachers College Record, v. 108, n. 6, p. 10171054, 2006. Disponível em $<$ http://punya.educ.msu.edu/publications/journal_articles/mishra-koehlertcr2006.pdf>Acessoem 06 de mar. 2016.

MISHRA, P.; KOEHLER, M. M. J. Introducing Technological Pedagogical Content Knowledge. In: Annual Meeting of the American Educational Research Association. New York City, March 24-28, 2008. Disponível em: <http://punya.educ.msu.edu/presentations/AERA2008/MishraKoehler_AERA2008.pdf>. Acesso em 09 mar 2016.

NÓVOA, A. Professores: Imagens do futuro presente. Educa: Lisboa, 2009.

NÓVOA, A. Devolver a formação de professores aos professores. Cadernos de Pesquisa em Educação, Vitória/ES, v. 35, n. 1, pp. 11-22, 2012. Disponível em: <http://periodicos.ufes.br/educacao/article/view/4927>. Acesso em: 10 maio 2015.

PONTA GROSSA. Secretaria Municipal de Educação. Diretrizes curriculares: ensino fundamental. Ponta Grossa. 2015. 224p.

PONTE, J. P. da. Tecnologias de informação e comunicação na formação de professores: que desafios? Revista Ibero Americana de Educación, Monográfico: TIC en la educación, n.24, pp. 63-90, 2000.

PONTE, J. P. da; FONSECA, H. Orientações curriculares para o ensino da estatística: Análise comparativa de três países. Quadrante, v. 10, n. 1, pp. 93-115, 2001. Disponível em: <http://repositorio.ul.pt/handle/10451/3035>. Acesso em: 4 jun. 2015.

SILVA, E. M. da C. Como são propostas pesquisas em livros didáticos de ciências e matemática dos anos iniciais do ensino fundamental. $133 \mathrm{f}$. Mestrado em Educação Matemática e Tecnológica - Centro de Educação, Universidade Federal de Pernambuco. Recife, 2013. 